\title{
Gênero, Instituições e Economia: uma visão feminista no mercado de trabalho
}

\author{
Emily Santos Mota ${ }^{1}$ \\ Igor Castellano da Silva ${ }^{2}$
}

\begin{abstract}
RESUMO
Perante a discussão sobre gênero no mercado de trabalho, os anos de 1970 foi um marco para o movimento feminista e para o processo de reestruturação produtiva. Após o período industrial, os questionamentos sobre as formas de se analisar os processos econômicos e até mesmo a própria economia passaram a ser questionados. Diante desses questionamentos e dúvidas surge a economia feminista, criticando o mainstream econômico por analisar os processos sem considerar os fatores históricos, psicológicos, experiências vividas, e hábitos construídos socialmente que determinam os processos decisórios individuais. As Instituições, dentro da sua pluralidade de definições, podem surgir tanto como organizações governamentais possivelmente atuantes de maneira formal por meio de normas e regulamentos de atividades, como também informalmente através de arranjos moldadores de comportamentos, pensamentos, cultura, hábitos e tabus em contextos coletivos e individuais. $\mathrm{O}$ artigo será dividido, além dessa introdução, Instituições e economia, a discussão do gênero como uma Instituição social, gênero e patriarcado, a discussão da economia do trabalho do ponto de vista feminista (abordando o ponto de vista institucional).
\end{abstract}

Palavras-Chave: Instituições, gênero, economia

\section{Gender, Institutions and Economy: a feminist vision in the labor market}

\begin{abstract}
Faced with the discussion of gender in the labor market, the 1970s were a milestone for the feminist movement and for the process of productive restructuring. After the industrial period, questions about the ways to analyze economic processes and even the economy itself began to be questioned. Faced with these questions and doubts, the feminist economy arises, criticizing the economic mainstream for analyzing the processes without considering the historical, psychological factors, lived experiences, and socially constructed habits that determine the individual decision-making processes. Institutions, within their plurality of definitions, can emerge both as governmental organizations possibly acting formally through activity rules and regulations, as well as informally through shaping behaviors, thoughts, culture, habits and taboos in collective contexts and individual. The article will be divided, in addition to this introduction, Institutions and economics, the discussion of gender as a social institution, gender and patriarchy, the discussion of labor economics from a feminist point of view (addressing the institutional point of view).
\end{abstract}

Keywords: Institutions, Gender, Economy

\section{INTRODUÇÃO}

Perante a discussão sobre gênero no mercado de trabalho, os anos de 1970 foi um marco para o movimento feminista e para o processo de reestruturação produtiva, conforme foi percebido no livro A mulher na sociedade de classes de HeleiethSaffioti. Desenvolveu-se, então, uma nova conscientização da luta pela emancipação da mulher. (SAFFIOTI, 2013) Ainda nos dias atuais, a análise das condições do mercado de trabalho para a mulher continua sendo uma problemática que exige atenção.

\footnotetext{
${ }^{1}$ Bacharela em Ciências Econômicas. Mestra em Economia e Desenvolvimento Universidade Federal de Santa Maria (UFSM). Email emilystsmota@gmail.com

${ }^{2}$ Doutor em Estudos Estratégicos Internacionais pela Universidade Federal do Rio Grande do Sul (UFRGS).
} 
Desde a década de 1970, com a inserção feminina no mercado de trabalho, diversos setores da economia passaram por grandes transformações em função dessa presença exercendo atividades antes praticadas apenas por homens.

Após o período industrial, os questionamentos sobre as formas de se analisar os processos econômicos e até mesmo a própria economia passaram a ser questionados. Diante desses questionamentos e dúvidas surge a economia feminista, criticando o mainstream econômico por analisar os processos sem considerar os fatores históricos, psicológicos, experiências vividas, e hábitos construídos socialmente que determinam os processos decisórios individuais. (TEIXEIRA, 2017)

Dentre os fatores deixados de lado pela economia tradicional está o patriarcado, instituição que precisou de cerca de dois mil e quientos anos para ser construído, e até os atuais tem sido o responsável por parte dos hábitos mentais considerados bons e agradáveis que concretizam a sub-valorização e marginalização da mão-de-obra feminina. (TEIXEIRA, 2017)

No período arcaico, em que as mulheres foram tratadas como primeira propriedade pelos homens e iniciando o processo da criação do patriarcado socialmente, os trabalhos braçais considerados proezas eram praticados apenas por homens por serem considerados fortes e capazes para tal feito. Os trabalhos domésticos, rotineiros e com pouca visibilidade eram destinados às mulheres por serem consideradas mais frágeis. Desde essa época até os dias atuais o patriarcado vem se sedimentando socialmente e afetando a formação do mercado de trabalho em função desses hábitos mentais construídos historicamente. Apesar de a sociedade moderna avançar com a entrada cada vez maior de mulheres no mercado de trabalho, o estabelecimento de papéis de dois mil e quientos anos atrás continua afetando a desigualdade de gênero no mercado de trabalho, de modo que as mulheres continuam passando por dificuldades para avançar na carreira, assumir postos de comando, e atuar em áreas consideradas masculinas, ou seja, de grande visibilidade e afeição social. (FLORIO e ROHENKHOL, 2018)

As Instituições, dentro da sua pluralidade de definições, podem surgir tanto como organizações governamentais possivelmente atuantes de maneira formal por meio de normas e regulamentos de atividades, como também informalmente através de arranjos moldadores de comportamentos, pensamentos, cultura, hábitos e tabus em contextos coletivos e individuais. Trata-se em específico do último conjunto citado, trazendo a discussão para o gênero e como ele se comporta como uma instituição social moldadora de hábitos, pensamentos e formadores de opiniões, trazendo desigualdades e dificultando avanços.

O artigo será dividido, além dessa introdução, Instituições e economia, a discussão do gênero como uma Instituição social, gênero e patriarcado, a discussão da economia do trabalho do ponto de vista feminista (abordando o ponto de vista institucional).

\section{INSTITUIÇÕES E ECONOMIA: UMA TEORIA EVOLUCIONÁRIA}

O institucionalismo é traçado de forma interdisciplinar, permeando a Ciência política, Economia e Sociologia. A depender da área em que for abordado, o seu conceito é mais bem definido e delimitado. Mas independente da área, o novo institucionalismo se subdivide em dois pontos: os conflitos nas relações de poder entre os indivíduos; e o papel das instituições no comportamento dos indivíduos, na racionalidade e na influência cultural (THÉRET, 2003)

A teoria institucional da Ciência política iniciou seu percurso no âmbito normativo, traçando o aspecto da filosofia moral. Inicialmente, na década de 1930, o foco foi às constituições, gabinetes, e parlamentos, enquanto que em 1960 houve uma tentativa de romper com a filosofia moral que gerou uma aproximação do behaviorismo não psicológico. 
Essa nova perspectiva de se fazer ciência tentava conduzir uma análise empírica teoricamente guiada, de modo que a análise dos resultados políticos deveria deixar de ser influenciada pelos atributos formais das organizações, e sim na informalidade do poder, e comportamentos políticos. (SCOTT, 1995)

$\mathrm{Na}$ sociologia, a teoria institucional se destaca mais do que em qualquer outro campo de estudo. Embora as instituições, como a Igreja, a escola, ou a família serem independentes entre si em seus objetivos, o indivíduo sempre será resultado criativo dessas instituições, fazendo-se perceber essa influência na divisão social de papéis, por exemplo, uma vez que a delimitação do papel social masculino ou feminino na construção social do gênero é intimamente influenciada pela igreja ou a família. As instituições relacionam-se direta e indiretamente com os indivíduos, criando padrões de pensamentos, formas de agir, e influência na escolha de caminhos a se perseguir (carreiras). Esse tipo de relação proporciona ao indivíduo uma espécie de "licença" que justifica quando o indivíduo toma decisões erradas e até proibidas. (SCOTT, 1995)

Diante do que foi citado anteriormente no processo evolutivo do institucionalismo na Ciência política e na sociologia, é possível perceber como na economia houve uma contradição e falta de coerência lógica na forma de avançar como ciência institucional. A antiga economia institucional compactuava com as novas abordagens avançadas da ciência política e da sociologia, de modo que os contextos históricos e culturais dos indivíduos estariam moldando os processos econômicos dentro de estruturas sociais. A nova economia institucional, no entanto, deixa de lado o contexto histórico e cultural e aposta no "homem econômico" que calcula milimetricamente cada ação e decisão que vai moldar a economia. Em função dessa contradição com o processo de avanço institucional nas demais ciências, há a necessidade dentro da economia de voltar a considerar o comportamento e características cultural-cognitivas na análise dos processos econômicos e nas estruturas sociais. (SCOTT, 1995)

A dificuldade de definição das instituições dentro da economia institucional está diretamente atrelada à forma como essa abordagem econômica engloba a totalidade de áreas, tornando-se distinta apenas na tipologia de especialidade da economia institucional que deve ser utilizada para tratar áreas específicas. As instituições econômicas podem estabelecer regras e normas nas pesquisas de desenvolvimento econômico e nos processos inovativos, assim como as instituições sociais podem estabelecer a criação de aspectos comportamentais, hábitos e tabus que direcionam a trajetória nas relações sociais, e consequentemente em diversos contextos econômicos. (SIMÕES, 2013)

Richard Scott entra, então, com a discussão sobre os três pilares da economia institucional, delimitando e expandindo melhor todo o aspecto da economia institucional que até então foi discutida (desde os antigos institucionalistas até a nova Economia Institucional), logo, estes pilares são: O regulador, o normativo, e o cultural cognitivo.

O pilar regulador, que se assemelha aos neoinstitucionalistas, necessita de um apoio formal, escrito e coercitivo para impor regras, cujo personagem principal é o Estado. Geralmente é abordado por historiadores econômicos, Douglas North, estabelecendo regras formais acompanhadas de crenças pré-estabelecidas. Considera-se, nesse pilar, que a busca pela satisfação das necessidades individuais e egoístas acontecem constantemente, de modo que os indivíduos e empresas a fazem racionalmente por meio da análise custo-benefício. $\mathrm{O}$ Estado como o principal regulador, estabelece seus próprios interesses e os fazem cumprir pelos demais atores sociais, estabelecendo regras que limitem os excessos de indivíduos e empresas que comprometam esses interesses estatais. (SCOTT, 1995)

Dando continuidade a descrição dos três pilares institucionais, o normativo atua como o que inclui valores e normas capazes de influenciar o comportamento humano. A partir do 
estabelecimento de metas (lucros ou ganhos do jogo, por exemplo) essas normas determinam funções para determinados grupos e controlam seus comportamentos para que as executem a fim de atingir tais objetivos. A concepção normativa é abordada por alguns sociólogos como Durkheim, e passou a se afastar a racionalidade total do indivíduo, aproximando-se da nova economia institucional e sua racionalidade limitada. (SCOTT, 1995)

O terceiro e último pilar, o cognitivo, preocupa-se com a mediação entre os estímulos externos e a resposta individual de cada organismo, ou seja, tudo que uma criança faz ou pensa estar certo está de acordo com o que se foi criado no ambiente daquele indivíduo. $\mathrm{O}$ interesse individual não mais é delimitado por uma instituição somente visando atingir uma meta pré-definida, e sim em função do que a construção social daquele ambiente considera como algo de interesse a se perseguir, ou seja, o que é de interesse de um determinado indivíduo que se encontra em determinada localidade, nem sempre coincide com o interesse de um segundo indivíduo numa localidade de cultura diversa do primeiro. Enquanto a perspectiva normativa é atingir uma meta normativa a partir de estabelecimento de valores e normas, os institucionalistas cognitivos enfatizam a identidade social: a própria concepção de quem se é, e os modos de ação que fazem sentido em cada situação. (SCOTT, 1995)

Dessa forma, muitos dos antigos institucionalistas, ThorsteinVeblen e John Commons, iniciaram suas discussões baseadas na preocupação com a criação social, expondo a importância da análise do indivíduo dentro da realidade não abordada pelos neoclássicos, levando em consideração experiências e comportamentos transmitidos socialmente no decorrer dos anos que impactam no processo decisório e na forma de agir. Estando amparada na própria biologia, repleta da capacidade de transformação no decorrer dos anos, as instituições para a maioria dos autores não só moldam os comportamentos como também tem a capacidade de transformá-los. (Hodgson, 2006)

Veblen, dentro do processo de desenvolver a teoria institucional que percorre a economia e adentra na sociologia, tornou claro alguns conceitos, como hábitos e instintos, que funcionam como suporte para se fazer entender essa teoria, dentro do pilar cultural cognitivo, conhecida como vebleniana, mostrando o caminho de conceitos que levou Veblen a elaborar a conceituação das instituições e seu papel social. (SILVA, 2010)

O instinto na teoria institucional vebleniana não limita os interesses individuais e coletivos apenas como fruto de uma condição fisiológica e totalmente inconsciente, como se a sobrevivência para o ser humano tivesse os mesmos pressupostos dos baixos animais, uma vez que para a condição humana, a inteligência e a racionalidade existem para que haja aproximação com o que exige as normas sociais, e os instintos e interesses precisam estar inclusos no que permitem ou não essas normas. Ao passar por um processo de criação histórica, os instintos têm suas características formadas também conscientemente e depende das características culturais de cada grupo, ou seja, a sobrevivência e as motivações de interesse são construídas com as experiências vivenciadas e disseminadas para as próximas gerações que estão por vir. A construção do conceito de instinto gera consequentemente a formação do conceito de hábito. (SILVA, 2010)

Os hábitos para Veblen não se tratam apenas de hábitos de vida, e na verdade, estes quando reproduzido em um largo espaço de tempo geram consequentemente hábitos de pensamento. As atitudes em períodos pretéritos servem de base para tudo que é considerado natural atualmente e é tido muitas vezes como hábitos de necessidade social. Assim como os instintos, funcionam como uma forma de despertar as ações sociais que estão fora da capacidade racional do indivíduo, justificando ações e decisões que inúmeras vezes não se conhece o porquê ou o como foram executadas ou tomadas respectivamente. Uma vez aceito e instaurado socialmente, os hábitos de vida se transformam em pensamento e seguem uma caminhada que se trilha em sua maioria no papel de continuidade ao invés de ruptura, 
estando, dessa forma, cristalizado em máximo potencial e atuando na percepção do que é certo e errado naquele grupo ou sociedade, conforme comenta Silva (2010, p. 298):

O hábito, uma vez consagrado socialmente, cristaliza-se de modo quase inabalável. Mesmo que o indivíduo não faça ideia de sua origem ou de sua aplicabilidade, o hábito pode persistir sem que ninguém ou nada o altere. Dessa forma, o sujeito está subordinado a imperativos que, no mais das vezes, fogem ao seu controle.

A cristalização de valores, com o estabelecimento de hábitos de pensamento, levou ao desenvolvimento do conceito de instituições. Do ponto de vista vebleniano, as relações sociais começam a estabelecer e compartilhar de rotinas que hegemonizam grupos sociais, passando a ser essa a principal função das instituições: unificar um grupo que se identifica simbolicamente por meio de crenças e ações estabelecidas historicamente e praticadas inicialmente de forma individual, e assim tornar essa característica permanente. (SILVA, 2010)

A trajetória, continuamente influenciada pelas instituições no decorrer dos anos, se forma e se transforma a partir de mudanças e rupturas no caminho pelo qual ocorrem os processos, sejam eles os de desenvolvimento ou os de mudanças sociais que geram transformações nas relações sociais. É preciso esclarecer que apesar das instituições sociais impactarem na trajetória dos processos sociais, não afasta essa tipologia da abordagem e das análises da economia institucional, uma vez que o comportamento e hábitos sociais construídos historicamente, as influências nas transformações cultural-cognitivas, mudam a forma de pensar e de se relacionar, e conforme as mudanças ocorram socialmente, a economia também vai se adaptando e se transformando. (CATANEO, 2009)

Independentemente de ser instituição econômica ou social, o path dependence se fará presente como uma trajetória orientada por acontecimentos do passado. Segundo Simões (2013) não significa que o passado será copiado para o presente na íntegra, no entanto, as instituições existem como veículos de transporte de determinadas características de períodos anteriores para os atuais. Apesar de construir normas ou comportamentos e hábitos, as instituições são capazes de se transformar e gerar rupturas de padrões que elas mesmas construíram, e uma vez rompido o padrão, ela também segue veiculando o transporte dessas novas características no decorrer dos anos.

Tratando as instituições como a base do processo de construção social de pensamentos e tabus, as relações sociais encontram-se amparadas na idéia institucional de criação e no processo de suas próprias transformações. O gênero, dessa forma, passa a ser tratado como uma instituição social por meio da dinâmica de se formar e se transformar em momentos históricos diferentes e em suas diversas sociedades, atribuindo papéis e estabelecendo limites de potencialidades. O ponto principal é que nada é tão natural que não pode mudar e evoluir.

\section{GÊNERO COMO INSTITUIÇÃO SOCIAL}

As instituições sociais como portadora de características e modos de pensar dos indivíduos também participa da associação do gênero como uma construção social, parte da dinâmica social. Segundo a socióloga Patrícia Martins, o gênero mobiliza a sociedade ideologicamente e em comportamentos, atuando de forma direta nas relações sociais e na atuação do Poder. (SOUZA, 2009)

A análise institucional do gênero, ou simplesmente tratar o gênero como a própria instituição social, permite o processo de transformação constante entre períodos históricos, diferentemente de algumas visões tradicionais do patriarcado, e dessa forma, o Path dependence não só veicula características e padrões dentro da ideologia de gênero 
historicamente construída, como também proporciona o mesmo processo de desconstrução. A instituição social traz como crítica então a possibilidade de transformação e evolução social a partir do constrangimento humano em função dos próprios comportamentos. (SOUZA, 2009)

A necessidade dessa discussão sociológica se mostra satisfeita ao se atingir as relações de poder, pois é a análise das suas mudanças que permeiam a economia institucional e do trabalho, abordando como as transformações de uma determinada instituição que anteriormente era cristalizada em limitações nas divisões de papéis se configura como um fator de orientação para repaginação do mercado de trabalho.

As instituições sociais segundo Lakatos (1997, pag. 74) são sistemas que estabelecem papéis em um código de conduta social para os cidadãos, e que também criam um padrão que designa a forma como essas instituições irão intervir de forma específica na sociedade. As principais instituições sociais são: Família, Empresa, Estado, Igreja e Escola.

Segundo Quintaneiro; Barbosa; Oliveira (2003) Durkheim possui uma discussão de referência sobre a relação do indivíduo com a coletividade e seu impacto na formação comportamental. Para ele, a sociologia é a própria "ciência das instituições, da sua gênese e do seu "funcionamento" - O teórico -

versa que as instituições regulamentam o comportamento social mediante uma influência autoritária na maneira de se portar, pensar, e até mesmo sentir. Essa intervenção externa que impacta o comportamento coletivo foi denominada de fato social.

O fato social, pelo ponto de vista de Durkheim, é um processo externo ao indivíduo, ou seja, o social ou dito "todo" impacta o processo criativo de forma padronizada das partes, embora sejam elas que forme o todo, não é a soma delas que resulta num comportamento global. Dentre os exemplos já mencionados anteriormente, a família é uma instituição social e interfere nas formas de pensar, de agir e de sentir de cada cidadão que compõe essa família. Dessa forma, a instituição familiar determina a não aceitação desse padrão e resulta em um constrangimento dessas regras por parte do componente familiar. (QUINTANEIRO; BARBOSA; OLIVEIRA, 2003).

A definição de mudança social estabelecida por Lakatos e Marconni (1999) é que "toda transformação observável no tempo que afeta, de maneira não provisória ou efêmera, a estrutura ou o funcionamento da organização social de dada coletividade e modifica o curso de sua história". A dinâmica pode funcionar de três formas: processo social, e evolução social. O ponto em comum entre elas é o acúmulo de transformações que ocorrem em um dado período de tempo, uma vez que a principal distinção entre a primeira e última fase é o tempo de acúmulo, ou seja, o tipo de transformação, sendo ele de curto e longo prazo respectivamente. Atuando como mediadora entre mudança e evolução, a transformação pode acontecer de forma benéfica, progressiva, planejada ou não. (CATANEO, 2009)

A autora Martin (2004) apresentou uma série de características das instituições sociais que auxiliam ou dificultam o indivíduo na sua forma de pensar e de agir, elas se enquadram inclusive na argumentação do gênero como instituição social que pode ser explanado como as questões sociais, a compreensão e as transformações dessa instituição impactam em outros campos de variáveis sociais, uma vez que essa relação é complexa e se encontra estabelecida historicamente.

Os movimentos feministas, anteriormente já mencionados nessa discussão, exemplificam bem essa interação e impacto, uma vez que a busca por mudanças na forma de pensar e agir por parte de homens e mulheres no contexto da sociedade gerou um acúmulo de mudanças, e consequentemente, um processo social, que à longo prazo tem ocasionado uma evolução social dentro da instituição gênero. O equivalente aconteceu com a família, escola, e principalmente no mercado de trabalho. 
Desse modo, as relações sociais constituídas no poder fizeram parte do processo de criação das desigualdades de gênero diante da divisão de papéis estabelecidas no processo histórico, ocasionando distribuições desiguais de cargos e transferindo à mão-de-obra mulheril funções estereotipadas como femininas relacionadas corriqueiramente a afazeres do lar: setor de costura, cozinha, limpeza, frequentemente associados a salários inferiores, enquanto que os homens possuíam com mais facilidade cargos de chefia e aqueles distantes da caracterização feminina. A equidade é ascendida pelas instituições que buscam amenizar essa disparidade e regular as relações no mercado de trabalho.

\subsection{Gênero e Patriarcado}

O conceito de gênero passou por diversas transformações no decorrer do tempo, estando sua construção inúmera vez atrelada ao sexo biológico em determinados momentos, ou sendo tratado como uma construção social com o apoio contemporâneo dos movimentos feministas, sendo embasada, de uma certa forma, pela divisão e estabelecimento de papéis distribuídos entre homens e mulheres historicamente. (RODRIGUES, s. d)

No dicionário, o conceito de gênero é aquilo que diferencia homens e mulheres em contexto biológico, aquilo que naturalmente determina o que é ser homem ou mulher. Mas segundo Rodrigues (s.d) se faz necessário estudar o homem e a mulher no contexto da construção social, levantando discussões com base na construção do que são papéis masculinos e femininos, e assim estabelecer análises acerca das relações sociais de poder que cercam homens e mulheres desde os tempos mais antigos até a contemporaneidade. Estudar homens e mulheres de forma relacional sai da idéia da homogeneidade da raça humana.

De acordo com Gaspari (2003) as mulheres desde o início foram levadas ao trabalho doméstico de reprodução e subordinação. Na educação, a mulher já sofria marginalização em relação à população masculina em não poder fazer parte da classe detentora do saber, e partir daí, o papel feminino ficou limitado e passou a ser considerado como aquele que tem pouco a acrescentar. Deste modo, um ser sem vontade própria e com poucos direitos de escolha, foi exigido como mãe e guardiã de costumes, assim como foi tratada e considerada inferior intelectualmente em relação a seus maridos.

No caminhar dos movimentos feministas, Simone de Beauvoir como uma escritora francesa que serviu de base para boa parte desses movimentos, estimulou a análise de que a mulher acaba por não possuí história, e que a única maneira dela se sentir humana e cidadã é adentrar no meio produtivo, iniciar um processo dentro da própria mulher que ela é um ser humano com direitos, deveres e capacidades a serem exploradas. A idéia de que a mulher é diferente do homem biologicamente, não justifica a desigualdade política, econômica e social em que ela é inserida mundial e historicamente. (BEAUVOIR, 1979)

A célebre frase de Beauvoir "não se nasce mulher, torna-se mulher" é exatamente o que aconteceu com o processo histórico de construção social do papel estabelecido como feminino aconteceu, e também o contrário, a quebra do paradigma da fragilidade feminina que as concentrava no lar e nos serviços domésticos. Com essa ressignificação, os conceitos passaram e estão passando ainda por revisão, uma vez que a mentalidade e a forma de enxergar a mulher social e economicamente de maneira diferente exige tempo, quebrando e desconstruindo pensamentos e hábitos que foram enraizados desde o início dos tempos até a época contemporânea. (RODRIGUES, s. d)

A partir dos anos de 1970 o movimento feminista ganhou força social e, juntamente com o período da ditadura militar, as mulheres também lutaram em prol da redemocratização do país, criaram grupos de discussão acerca dos problemas do meio feminino, e também estiveram em busca da melhor divisão sexual do trabalho. Dessa forma, começou a ser 
disseminada a visão de um mundo melhor, de modo que as diferenças levariam os indivíduos (homens e mulheres) a procurarem apoio entre si ao invés de lutarem por poder, e assim, criar uma sociedade melhor e com maior equidade entre os gêneros. (GASPARI, 2003)

A igualdade de gênero é a busca principal no feminismo, levando em consideração as diferenças entre homens e mulheres, e entre as próprias. Diferentemente do que se acha, o feminismo não exige que as mulheres se tornem homens, uma vez que diferença versus semelhança é uma discussão necessária tão importante quanto a diferença entre igualdade versus desigualdade. O que é diferente também pode compartilhar do quesito qualidade, direitos e deveres em proporções de igualdade, não existindo dentre os diferentes, o que é mais ou menos importante. (BEAUVOIR, 1979)

Discutir sobre o feminismo e suas bases que levam a maior equidade entre os gêneros e não falar do patriarcado amputa analiticamente um dos grandes problemas femininos acerca da desigualdade entre homens e mulheres quanto à construção social de papéis. O conceito sociológico do patriarcado que permeia as discussões de gênero é dado por Klinenberg (1967, p. 364) como "aquele que designa o total de padrões de cultura associados com um status em particular". No conceito estabelecido por Weber (2000, p. 184) chama-se patriarcalismo "a situação na qual, dentro de uma associação, na maioria das vezes fundamentalmente econômica e familiar, a dominação é exercida (normalmente) por uma só pessoa, de acordo com determinadas regras hereditárias fixas".

A cultura do patriarcado dentro da análise institucional cognitiva aplica-se como o aprendizado de papéis internalizados conforme os indivíduos se identifiquem em um grupo social. Dentro de cada período histórico e em diversas culturas, o patriarcado se instalou com base na idéia da propriedade privada, não só de bens, mas também na posse do homem pelo homem, e no papel atribuído ao homem dentro do meio privado (reprodutivo). A dominação masculina passou a ser aceita e se tornar crescente nas diversas culturas e sociedades, tornando a mulher hierarquicamente subordinada e incapaz de tomar suas próprias decisões, trazendo como conseqüência a extrema desigualdade na divisão sexual do trabalho. (BARBOSA et. Al, 2011)

O patriarcado, no entanto, possui críticas e conceitos baseados em diversos pontos de vista que diferem quanto ao tipo de análise segundo Morgante e Nader (2014). No ponto de vista de HeleiethSaffioti, a base marxista da dominação do homem sobre a mulher inicia no âmbito familiar e adentra na problemática do capitalismo, mulheres exploradas marginalmente e consideradas inferiores na divisão sexual do trabalho. Na visão Weberiana, o patriarcado trata da dominação masculina nas construções familiares, no entanto, Mary Castro e Lena Lavinas discordam da visão de Weber e consideram o patriarcalismo um termo heterogêneo, presente em diferentes famílias contemporâneas e impregnado na própria dinâmica social.

Quando utilizado em apenas uma perspectiva, o patriarcado limita-se a idéia de superestrutura e da dominação masculina na divisão sexual do trabalho, deixando de administrar toda construção histórica e cultural por trás da própria exploração, e atribuindo a essa estruturação uma caracterização definitiva. A essência do patriarcado de construção social e cultural também precisa ser abordada no âmbito do constrangimento dessa estrutura cristalizada, mostrando o processo de mudança na aprendizagem e na forma de reestruturação nas relações sociais e na forma de pensar. (MORGANTE e NADER, 2014)

Ficou perceptível o quanto o processo institucional na formação das relações de gênero e também a atuação do patriarcado podem afetar outras instituições. O mercado de trabalho também passa por processos de reestruturação conforme haja o constrangimento dos hábitos e a descristalização das formas de pensar individuais, e com isso, a economia do 
trabalho passa por uma reforma analítica e insere a problemática da mulher em suas discussões e abrangendo uma perspectiva feminista no mercado de trabalho.

\section{ECONOMIA DO TRABALHO: UMA PERSPECTIVA FEMINISTA}

A economia do trabalho estuda a força de trabalho dentro do processo produtivo, sua base teórica analisa os fatores que afetam a eficiência, ou seja, como ocorre a alocação das diferentes ocupações em um público heterogêneo, e suas determinantes formas de pagamento.

O trabalho, desde as suas raízes históricas que o tratava como produção necessária para sobrevivência humana, tem seu conceito transformado até os dias atuais a partir de cada vivência das diferentes civilizações em diferentes épocas, tanto no que se refere a articulação dos agentes, quanto os conteúdos das diversas formas de trabalho e suas segmentações de papéis. Cada um desses fatores passou por um processo de mutação no seu conteúdo analítico conforme o trabalho exercido adentra a frente no tempo.

As transformações do mercado de trabalho, que acompanham as mudanças de uma sociedade contemporânea, levam ao surgimento de mudanças necessárias quanto às funções institucionais que regem e coordenam esse mercado de trabalho. Uma vez que o processo de mutação social se inicie, as instituições possuem suas demandas funcionais modificadas ou até mesmo expandidas para atender a uma nova sociedade que se posiciona de forma diferenciada no mercado de trabalho referente as remunerações, ocupações e segmentações relacionadas a capacidades de execução. (REIS, 1997)

O processo transformador não foi desencadeado apenas no trabalho, mas também alcançou a forma de se analisar os processos econômicos e a própria economia. Um dos principais motivos para tal foi o surgimento da economia feminista no período da sociedade industrial, que ao introduzir o estudo de gênero na ciência econômica, vem tentando alargar o número de ferramentas antes ignoradas pelo mainstream econômico. (FLORIO e ROHENKOHL, 2018)

A economia feminista possui um ponto tangencial com a economia institucional, uma vez que ambas concordam que para se compreender o caminhar dos processos econômicos de uma sociedade, antes é necessário se fazer entender a construção social por trás dela. Dentre os diversos argumentos e vertentes da economia feminista, a que se intercepta com a economia institucional é segundo Teixeira (2017, p. 59) aquela em que "a realidade é uma complexa interação de forças mercantis e não mercantis, de relações de classes e de gênero que estão entrelaçadas e agem de forma simultânea". O mainstream ao considerar o indivíduo como racional, que não tem passado e não passou por nenhum processo de formação social, limita todas as decisões econômicas em torno da maximização da utilidade, distanciando-as do contato social individual.

Analisar a economia feminista não se faz possível sem tratar da economia social, uma vez que esta associa-se à economia em contextos culturais, políticos e sociais, ou seja, tais contextos influenciam nas decisões econômicas diferentemente do que acredita o Mainstream. (FRANÇA FILHO, 2002) As instituições atreladas à economia social preocupam-se principalmente com as demandas sociais, buscando reduzir as desigualdades e discriminações sociais. (OBESP, 2011) Essa nova forma de se fazer ciência, analisando o contexto de forma mais real e por trás das cortinas, possui duas vertentes de análise: Economia feminista de conciliação, e Economia feminista de ruptura. (TEIXEIRA, 2017)

A Economia feminista de conciliação, em primeiro lugar, busca tornar visível o trabalho reprodutor redefinindo o conceito de trabalho. Em segundo lugar, discutem afinco as desigualdades nas relações sociais de gênero afim de compreender as relações econômicas mais a fundo mediante a junção dos conceitos de gênero, sexo e patriarcado. $\mathrm{O}$ terceiro ponto 
analisa a desigualdade nas causas do que é considerado mercado e o que não é considerado mercado, estando esta evoluindo cada vez mais nas discussões dentro da metodologia da economia feminista.

A Economia feminista de ruptura reconhece que o trabalho produtivo e reprodutivo de fato tem diferenças principalmente no cabe a importância dada a cada um deles, desta forma, traz a reflexão de que o bem-estar social não está atrelado apenas ao lucro, mas também ao afeto e às relações. Nessa perspectiva de análise, o trabalho doméstico ou o serviço do cuidado tem importância na melhoria de vida da população. Em função disso, deveria ser mais valorizado e redistribuído com os homens na vida doméstica, visando melhorar a qualidade de vida das mulheres, que muitas vezes se financeira da casa.

Não só do ponto de vista institucional, mas também o social, a ciência econômica na sua vertente ortodoxa não leva em consideração as interações sociais (hábitos, costumes, crenças), e determinam superficialmente as decisões individuais com base no lucro, deixando de lado todo interdisciplinaridade e pluralidade nas metodologias de análise econômica. (TEIXEIRA, 2017) A economia feminista, apoiada nesses dois pontos de vista, esclarece que as escolhas das mulheres nem sempre estarão de acordo com o que diz a teoria tradicional, uma vez que seus papéis e responsabilidades mais têm a ver com o que foi construído culturalmente do que uma decisão racional baseada em lucro. Essa nova forma de vê a economia não se preocupa em estudar a economia das mulheres, mas traz a reflexão de que essa classe não pode ser analisada de forma tão simplista como pede o tradicionalismo econômico, uma vez que o processo construtivo da mulher socialmente não aconteceu igual aos homens. (GRANOVETTER, 1985)

As mulheres foram ignoradas pelo pensamento econômico, que negou a elas o direito de criar conhecimento e o estatuto de sujeito de direitos políticos e econômicos, além da condição de agentes economicamente ativos, ao estabelecer uma distinção entre o econômico e o não econômico, o trabalho e o não trabalho. (TEIXEIRA, 2017)

E apesar de não existir nessa vertente a intenção de estudar exclusivamente um lado da economia que foi ignorado (o feminino), entender a formação da classe ociosa e da propriedade pela ótica de gênero enriquece a análise econômica tanto para questões masculinas como para questões femininas. A forma como se deu a construção social em torno do pré-estabelecimento de papéis implica na forma de pensar, de agir, e de se relacionar socialmente, afetando não só os processos econômicos como também a economia. (FLORIO e ROHENKOHL, 2018)

A economia feminista surgiu em meados de 1970 como uma crítica ao modelo do mercado de trabalho da época. As decisões do homem englobavam as decisões da esposa, e o trabalho doméstico era considerado lazer, não se fazendo presente nas contas nacionais. $\mathrm{O}$ trabalho feminino, e seu papel de proporcionar bem-estar, que de uma forma ou de outra contribui com o alavanco da carreira masculina foi deixada de lado e tratada como invisíveis. (NELSON 2005)

A classe ociosa é reflexa de uma divisão social de papéis desde o período arcaico, quando homens, atuantes em um estilo de vida bárbara, demonstravam o seu valor socialmente com a conquista de terras e vencendo batalhas. Historicamente, esse tipo de trabalho era visto como proeza pelo resultado que realizava, enquanto que os trabalhos rotineiros (cuidar da casa e dos filhos) eram vistos como indignos por ser um ato reprodutivo e diário. (VEBLEN, 2003)

A distinção entre proeza e trabalho penoso coincide com uma diferença entre os sexos. Os sexos diferem, não só em estatura e força muscular, mas talvez ainda mais decisivamente em temperamento, e isso deve ter dado início a uma correspondente divisão do trabalho. As atividades que em geral se classificam como proezas tocam aos homens, porque são mais 
fortes, mais firmes, mais capazes de tensão súbita e violenta, e mais facilmente inclinados à auto-afirmação, à emulação ativa e à agressão. (VEBLEN, 2003, P. 11)

A propriedade surgiu como uma forma de demonstrar poder no período arcaico, e Veblen (2003) argumenta que a primeira e mais primitiva forma de propriedade envolve a dominação do homem sobre a mulher. Ao ser confiscada nos períodos de guerras como troféu, dando origem aos casamentos por propriedade, foi estereotipada a figura do homem chefe de família autoritário e com benefícios, e da mulher submissa e inferior em suas atribuições.

\section{CONCLUSÃO}

Toda abordagem institucional acerca do papel feminino no mercado de trabalho está diretamente atrelada ao modelo institucional que rege a construção social em aspectos culturais e cognitivos, seja ele nas formas de pensar ou de agir do indivíduo e, consequentemente, da sociedade, e assim se fazer perceber como a criação do pensar do que é certo dentro das relações sociais estão influenciando o estereótipo feminino na divisão de papéis dentro de Instituições sociais e econômicas. Durante o processo de criação da ciência institucional, a ciência econômica tem buscado trazer o centro de análise para esse novo contexto, e na dinâmica do mercado de trabalho, tornar possível e mais realista a discussão dessas dinâmicas por meio da economia feminista que antes não eram presenciadas ou percebidas pelos modelos normativos e reguladores.

O gênero e o patriarcado comportam-se como uma Instituição social quando tem o poder de atuar na divisão social do trabalho, na caracterização do feminino e do masculino, quando há a dificuldade de ascensão em carreiras em função do que foi estereotipado em períodos passados e perpetuados em períodos futuros, e na construção dos hábitos. Essa nova perspectiva tráz maior realidade para análises de mercado de trabalho, pois inclui aspectos antes não levados em consideração e que em contextos mais profundos, impactam em grande escala proporcionalmente a distribuição de gênero no mercado de trabalho

\section{REFERÊNCIAS}

BEAUVOIR. In: Nova Enciclopédia de Biografias. Rio de Janeiro: Planalto Editorial, 1979. v. 1. p.120.

BOURDIEU, Pierre. A Dominação Masculina. Tradução de Maria Helena Kühner. Rio de Janeiro: Bertrand Brasil, 2003 [1998].

CATANEO, M. E. Conhecendo Ambientes Educativos : livro didático; design instrucional Carmen Maria CiprianiPandini. - Palhoça :UnisulVirtual, 2009.

Economia e sociedade: fundamentos da sociologia compreensiva. Brasília:

Editora da Universidade de Brasília, vol. I e II, 1999.

FRANÇA FILHO, G. C. de. Terceiro Setor, Economia Social, Economia Solidária e

Economia Popular: traçando fronteiras conceituais. Rev. Bahia Análise e Dados. Junho de 2002, vol. 12, n. 1, p. 9-19. ISSN 0103 8117. Disponível em:

<https://intranet.dcc.ufba.br/pastas/ondadigital/backupAnexoSite/incluiSim/EconomiaSolidria - FronteirasConceituais.pdf> 
HODGSON, G. Institutions and economic development: constraining, enabling and reconstituting. In: DYMINSK, G.; DE PAULA, S. (Ed.). Remaining growth: towards a renewal of Development Theory. London: Zed Books, 2005. p. 85-98

KLINENBERG, O. Psicologia Social. $3^{\text {a }}$ edição. Rio de Janeiro: Editora Fundo de Cultura, 1967.

MARTIN, P.Y. (2003). Gender As Social Institution. Louisiana: Southern Sociological Society.

PROBST, E.R. A Evolução da mulher no mercado de trabalho. Disponível em: . Acesso em: 25 setembro 2016.

Rodrigues, V. L. A importância da mulher. Acesso em:

http://www.diaadiaeducacao.pr.gov.br/portals/pde/arquivos/729-4.pdf

SAFFIOTI, H. A mulher na sociedade de classes. 3 ed. São Paulo: Editora Expressão Popular, 2013.

SIMÕES, A. Instituições e desenvolvimento econômico: os contrastes entre as visões da nova economia institucional (NEI) e dos neoinstitucionalistas. Universidade Federal do Rio de Janeiro. Rio de Janeiro. 2013.

SOUZA, M. F. da P. de. GÊNERO E DESIGUALDADE SOB O ENFOQUE

INSTITUCIONAL. Revista Eletrônica de Ciências Sociais, Juiz de Fora, v. 7, n. 3, p.42-57, ago. 2009

TEIXEIRA, Marilane Oliveira. Um olhar da economia feminista para as mulheres: os avanços e as permanências das mulheres no mundo do trabalho entre 2004 e 2013. 2017. 228 f. Dissertação (Mestrado) - Curso de Ciências Econômicas, Universidade Estadual de Campinas, Campinas, 2017.

THÉRET, Bruno. AS INSTITUIÇÕES ENTRE AS ESTRUTURAS E AS AÇÕES. Lua Nova, v. 11, n. 58, p.226-257, nov. 2003.

VEBLEN, T. A teoria da classe ociosa: um estudo econômico das instituições. São Paulo: Abril Cultural, 1983

The Instinct of Workmanship and the State of Industrial Arts (1 ${ }^{\mathrm{a}}$ edição: 1914). New Brunswick: Transaction Publishers.1989.

WEBER, Max. Burocracia. In: GERTH. H. H.; MILLS, C. Wright (Org.). Max Weber Ensaios de Sociologia. 5. ed. Rio de Janeiro: LCT, 2008.

WEBER M. Economia e Sociedade. $3^{\text {a }}$ edição. Brasília, DF: Editora Universidade de Brasília, 2000 .

Recebido: 29/09/2020

Aceito: $17 / 05 / 2021$

Publicado: Agosto de 2021

Revista Desenvolvimento Socioeconômico em debate v.7 n.1 (2021) 